\title{
Concepções pedagógicas e método de ensino: O manual didático Processologia na Escola Primária
}

\author{
Vera Teresa Valdemarin \\ Daniela Gonçalves do Santos Campos \\ Universidade Estadual Paulista Júlio de Mesquita Filho, Araraquara-SP, Brasil
}

\begin{abstract}
Resumo: Esse artigo analisa o manual didático Processologia na Escola Primária, de autoria de Caio de Figueiredo Silva, publicado em 1956, com o objetivo de compreender o processo de incorporação das concepções pedagógicas da Escola Nova nas prescrições para a prática pedagógica. O método empregado foi a análise do discurso expresso na fonte primária aliada a um conjunto de referências bibliográficas de cunho historiográfico que possibilitaram comentar o processo de inovação e permanência na educação, ressaltando as influências de tradições já estabelecidas e a importância dos textos didáticos como instrumentos mediadores para a difusão e circulação de idéias.
\end{abstract}

Palavras-chave: Manual didático. Concepções pedagógicas. Escola nova.

\section{Pedagogical conceptions and method of teaching: The textbook Processologia na Escola Primária}

\begin{abstract}
The article focuses on the analysis of the textbook Processologia in Primary School, by Caio de Figueiredo Silva, published in 1956. The goal is to understand the process of incorporating pedagogical conceptions from the Progressive School in prescriptions to the pedagogical practice. The method used was the analysis of speech expressed in primary sources allied to historical references. The textbook allows to elucidate aspects of innovating pedagogical ideas and maintenance processes in education. It seems to be possible to show the influence of established tradition and the importance of textbooks used as instruments for the diffusion and circulation of ideas.
\end{abstract}

Keywords: Textbook. Pedagogical knowledges. Progressive education.

\section{Concepciones pedagogicas y metodo de enseñanza: el manual Processologia na Escola Primária}

Resumen: Ese artículo analiza el manual didáctico Processologia na Escola Primária, de autoría de Caio de Figueiredo Silva, publicado en 1956, con el objetivo de verificar la articulación entre prácticas preescritas y concepciones teóricas. El método usado fue la análisis del discurso expreso en la fuente primaria con analices históricas que posibilitaran comentar el proceso de innovación y permanencia en la educación resaltando la influencia de tradiciones ya establecidas y la importancia de los textos como instrumentos didácticos mediadores para la difusión y circulación de ideas.

Palabras clave: Manual didáctico. Concepciones pedagógicas. Educación nueva. 
Estudos sobre a história das idéias pedagógicas costumam considerá-las a partir de alguns marcos de circulação em determinados contextos, vinculando-as a tendências filosóficas ou sociais a fim de traçar-lhes a linha de continuidade ou de inovação. No entanto, quando considerados na perspectiva da influência que exerceram sobre as práticas pedagógicas, os marcos de inovação baseados nas concepções doutrinárias se tornam menos precisos e emergem outras questões importantes para a compreensão da relação entre esses elementos da pedagogia: as diferentes interpretações dadas aos princípios teóricos; a relativa autonomia das atividades práticas ancoradas em esquemas de atuação profissional consolidados; a organização de um discurso consensual no qual interferem políticas públicas para a formação de professores e objetivos sociais postos para a escolarização em seus diferentes graus; a adaptação dos princípios aos diferentes conteúdos a serem ensinados e a criação de dispositivos mediadores para sua efetivação, entre outros aspectos.

A compreensão desse processo de transformação de proposições teóricas em prescrições para a prática pedagógica requer fontes de estudo específicas e os manuais didáticos produzidos para uso de professores são documentos pertinentes a essa investigação, pois têm como objetivo influenciar a prática pedagógica por meio da formação escolar e incorporam as discussões conceituais do período de sua produção a fim de se legitimar no campo pedagógico. Embora as atividades compiladas nos manuais não devam ser tomadas como efetivamente realizadas, sua prescrição é legitimada pelos próprios autores como o registro e a síntese de práticas bem sucedidas e avalizadas pela experiência docente: os autores desse tipo de impresso amparam-se em sua própria experiência de magistério e na ocupação de cargos na hierarquia burocrática escolar. Além disso, demonstram familiaridade e domínio da literatura pedagógica sendo capazes de nela discriminar os aspectos que podem ser transformados em orientações para a prática, além de conhecerem a legislação educacional e buscarem alternativas para a introdução de inovações. Ao serem configuradas como manual didático, as prescrições passam a compor um discurso racionalizado do que deve ser a prática pedagógica e, portanto, re- gistro documental do pensamento pedagógico de um período, que tem como objetivo principal constituir-se em ação docente.

Nessa perspectiva, analisamos o manual didático Processologia na escola primária, de autoria de Caio de Figueiredo Silva, publicado em 1956 pela Editora do Brasil (Coleção Didática do Brasil), que teve circulação e uso bastante expressivos nas escolas públicas do interior do estado de São Paulo, na região de São Carlos, com o objetivo de compreender o processo de incorporação das concepções pedagógicas da Escola Nova nas prescrições para a prática docente, de modo a verificar as articulações estabelecidas entre a teoria e os procedimentos didáticos.

Decorridos já vinte e cinco anos do período de discussão e proposição do ideário escolanovista no Brasil, a publicação do referido manual pode ilustrar os aspectos que se incorporaram ao discurso e à prática pedagógica trazendo elementos para comentar o processo de inovação e permanências na educação, valendo-se das indicações propostas por Viñao Frago (2006) que ressalta a força de tradições já estabelecidas e a importância dos instrumentos mediadores criados para a difusão e circulação de idéias, como é o caso do livro aqui analisado.

Embora dialogando com estudos sobre outros impressos também dedicados à orientação da prática docente, tais como os periódicos educacionais e as coleções pedagógicas, a presente análise insere-se num projeto de pesquisa que prioriza o manual didático produzido para uso de professores como fonte documental específica, desenvolvido no Grupo de Estudos e Pesquisas sobre Cultura e Educação (GEPCE) da Faculdade de Ciências e Letras de Araraquara da Universidade Estadual Paulista Júlio de Mesquita Filho.

\section{A produção e circulação da inovação educacional}

Apoiando-se na materialidade do impresso destinado aos professores, Marta Carvalho enuncia a constituição diferenciada dos saberes pedagógicos no início do período republicano e nas décadas de 1920 e 1930. No período final do século XIX e início do século XX o campo pedagógico é concebido como 
arte aplicada, como saber fazer, como prática que se apóia na imitação de modelos fornecidos quer pela observação de práticas exemplares quer pela aplicação de roteiros de lições, também oferecidos como exemplos. A autora esclarece que, diferentemente do sentido pejorativo empregado anos mais tarde pelos críticos, "falar aqui em cópia de modelos, é falar em um tipo de atividade que, partindo da observação de práticas de ensinar, é capaz de extrair analiticamente os princípios que as regem e de aplicá-los inventivamente" (Carvalho, 2001, p. 148, grifos da autora).

A síntese das proposições do campo pedagógico assim definido, encontra-se materializada nos modelos de exercícios escolares veiculados em diferentes impressos: nos manuais didáticos, nos programas de estudos que constituem o currículo, na repartição do tempo escolar que hierarquiza conhecimentos e habilidades a serem adquiridas, nos objetivos para a formação de professores e na seqüência de atividades articuladas de modo a compor um método para ensinar, atestando sua importante função para a docência.

A Pedagogia da Escola Nova ou Pedagogia Progressiva, ao ser disseminada a partir da década de 1920, estrutura discursivamente o campo pedagógico em outros termos, cuja diferença mais evidente, porque incide sobre o aspecto mais formalizado, é o não oferecimento de modelos para o ensino, mas da proposição de fundamentos, pretendendo substituir a pedagogia como arte pela pedagogia científica: "A pedagogia deixa de fornecer cânones para oferecer fundamentos" na expressão de Carvalho (2001, p. 154). O campo pedagógico passou a ser estruturado a partir de um conjunto de informações cujos referenciais estariam, principalmente, na sociologia, na biologia e na psicologia, divulgado por meio de coleções bibliográficas disponibilizadas aos professores a partir das quais seria possível a derivação para práticas diferenciadas, voltadas para contextos e clientela específicos. Nessa fase,

O livro único de pedagogia, espécie de manual em que se compendia o conjunto dos saberes representados como necessários e suficientes ao exercício da prática docente, tende a ser substituído por coleções pedagógicas. Nessas bibliotecas para professores, o recorte temático efetuado pela seleção dos títulos que integram a coleção subordina-se ao intento de constituir uma cultura pedagógica que sirva de fundamento e de critério para o exercício da prática docente. Trata-se de fornecer um repertório de informações e de referenciais críticos para o professor, orientando-lhe a leitura como prática inventiva rebelde à prescrição de modelos. (...) Nesse campo normativo, o que importa é constituir uma cultura pedagógica, compondo-se um repertório de valores e de conhecimentos destinados a balizar a prática docente. Para tanto, importa suscitar novos hábitos de leitura no professorado, propondo-se roteiros de leitura e prescrevendose modos de ler e utilizar o lido. Constituir coleções de livros especialmente destinados aos professores é estratégia adequada para a realização desses objetivos (Carvalho, 2001, p. 154-155, grifos da autora).

Nessa perspectiva, podem ser consideradas as diferentes estratégias para a divulgação das novas bases educacionais, que abrangem impressos e novas configurações institucionais tais como, a organização da Bibliotheca de Educação por Lourenço Filho, publicada pela Companhia Melhoramentos, de 1927 a 1941 (Monarcha, 1997; Carvalho \& Toledo, 2004, 2006, 2007); a coleção Atualidades Pedagógicas coordenada por Fernando de Azevedo, entre 1931 e 1946 (Toledo, 2001) e os diferentes periódicos educacionais (Cunha, 1992; Catani \& Bastos, 2002; Catani, 2003; Biccas, 2001, 2005; Bastos, 2005; Campos, 2005). No plano político-institucional é preciso considerar a solicitação de Lourenço Filho, em 1930, então Diretor da Instrução Pública de São Paulo, para que os próprios professores elaborassem os Programas de Ensino; as iniciativas de Anísio Teixeira e Lourenço Filho para a formação de professores no Instituto de Educação do Distrito Federal, de 1932 a 1937 (Lopes, 2006; Pinto, 2006; Vidal, 2001), voltadas para os mesmos objetivos.

Assim, pode-se acompanhar nas décadas de 1920 e 1930 as diferentes iniciativas, de cunho teóri- 
co e de cunho prático, para divulgação das concepções da Escola Nova, de modo a caracterizá-las como as inovações necessárias às novas condições políticas e econômicas do país, com uma mudança bastante nítida na estratégia para fazê-las circular e serem incorporadas ao cotidiano escolar. O livro permanece sendo o grande veículo de divulgação, tratase de "uma aposta cultural depositada no livro: a de promover a reforma da sociedade pela reforma da escola" (Carvalho \& Toledo, 2004), mas são livros estruturados em consonância com os novos princípios educacionais. Inspiradas principalmente nas proposições de John Dewey e Willian Kilpatrick as diretrizes da educação progressiva vão priorizar o contexto no qual se desenvolve a escolarização: as experiências do aluno, a sociedade na qual está inserido, o desenvolvimento da autonomia para a realização de trabalhos e atividades, a diversificação de ambientes educacionais, entre outros aspectos. Coerentemente, a bibliografia produzida na educação brasileira vai enfatizar, primeiramente, a reflexão sobre a função social da educação, seus elementos e determinantes já que sua aplicação encontra-se na dependência do ambiente e das condições dos alunos variando, portanto, as possibilidades de como fazer de acordo com o contexto.

O livro Introdução ao Estudo da Escola Nova de Lourenço Filho, obra fundamental na estratégia de divulgação das novas bases educacionais, apresenta-as como tributárias de um conjunto de conhecimentos então recentes, provenientes da história, da biologia, da psicologia e da sociologia. Descreve ainda a transformação sofrida pelos métodos de ensino e a elaboração de iniciativas inovadoras tais como os sistemas desenvolvidos por Montessori, Decroly (com os centros de interesse), os projetos e as unidades de trabalho. No mesmo texto, o autor define a problemática originada da relação entre as finalidades da educação e sua instrumentação mas, afirma que "o que caracteriza os sistemas e, assim, a direção da reflexão filosófica são os pressupostos que ela admita, para desenvolver seus métodos" (Lourenço Filho, 1978, p.230). Trata-se então, de explicitar os princípios gerais da Escola Progressiva de modo que deles possam decorrer as práticas: 1) "o respeito à personalidade do educando ou o reconhecimento de que deverá ele dispor de liberdade" (Lourenço Filho, 1978, p. 246); 2) a coordenação de atividades em funções que variam segundo a idade ou grau de desenvolvimento do aluno: "Assim, o interesse ensinará a disciplina e o esforço. De qualquer forma, aprender-se-á a fazer fazendo, e a pensar pensando, em situações definidas" (Lourenço Filho, 1978, p. 247); 3) organização da escola como uma pequena comunidade para que a aprendizagem simbólica se dê em situações de vida social; 4) oferecimento de oportunidade educacional a todos para garantir seu desenvolvimento. Resumindo:

Quando bem se examinem os princípios gerais da escola nova, como as condições acima referidas, verifica-se que a dimensão própria da ação educativa é de ordem social e cultural. É essa dimensão que enlaça a instrumentação e a finalidade, reclamando uma compreensão de ordem funcional geral, como complexo empreendimento da vida coletiva, por ação conjunta, ação política, no mais largo sentido desta expressão(Lourenço Filho, 1978, p. 249, grifos do autor).

Assim, a estratégia inicial de divulgação das concepções da Escola Nova priorizou o estabelecimento das novas bases teóricas, descrevendo algumas iniciativas metodológicas delas decorrentes, sem prescrever modelos de como ensinar mas asseverando a diversidade de possibilidades já implementadas, dado que a inovação foi concebida primeiramente como mudança de mentalidade e posteriormente como visível em novas práticas. Sendo a mudança de mentalidades um processo longo, a apropriação das novas concepções se deu, a princípio, pela incorporação discursiva de elementos próprios da nova concepção que conviveu com a permanência de antigas práticas justificadas de modo novo, conforme atestam estudos baseados em diferentes fontes ${ }^{1}$.

\footnotetext{
${ }^{1} \mathrm{O}$ manual Escola Brasileira, de João Toledo ilustra a afirmação da incorporação das novas concepções no plano discursivo aliadas à prescrição de práticas pedagógicas consolidadas; o manual Práticas Escolares, de Antonio D’Ávila exemplifica a tentativa de gerar práticas diferenciadas fundamentadas nas novas concepções.
} 
Na imprensa periódica os professores também atestam a incorporação do novo léxico pedagógico e, por meio de relatos de experiências realizadas, podese perceber a valorização das excursões pedagógicas (mesmo que seja por meio de "viagens simuladas"), a criação do cantinho de ciências e da biblioteca de classe, o uso de recursos audio-visuais e inovações em temas específicos do conteúdo a ser ensinado. No entanto, em um artigo publicado em 1952 na Revista de Educação há um balanço da educação no qual encontram-se críticas ao ensino verbalista e distante das necessidades do aluno e a defesa de um processo que considere as peculiaridades da criança e seus interesses e o apoio em realidades concretas que evidenciem a aplicabilidade do conteúdo desenvolvido. Aponta-se também a extensão do programa oficial como empecilho para a introdução de inovações e a necessidade da formação de professores incorporar a evolução operada no mundo da pedagogia (Pimenta, 1952).

Assim, é possível afirmar que os debates acalorados presentes na década de 1930 sedimentaram algumas diretrizes para o ensino e, nas décadas seguintes, verificou-se o esforço de professores, mesmo incidindo sobre aspectos pontuais, para transformá-las em práticas pedagógicas. Diferentes fontes devem ser analisadas para a compreensão do processo de transição entre as duas concepções: manuais de pedagogia, reformas educacionais em diferentes estados, coleções pedagógicas, periódicos especializados e troca de correspondência, conforme já apontado por Carvalho $(2001,2002)$. O eixo em torno do qual se estruturam essas duas concepções pedagógicas - a pedagogia como arte e a pedagogia de fundamento científico - é a articulação entre a teoria e a prática, o campo doutrinário da pedagogia e ações para efetivá-la como prática, diferentemente construída em cada uma delas. No entanto, a prática docente numa sociedade cuja demanda escolar cresce muito nos anos subseqüentes, principalmente no estado de São Paulo, problematiza a concepção da Pedagogia da Escola Nova e seu corolário de negação de modelos de aulas e lições.

Publicado no ano de 1956, quando as disputas entre as duas concepções já perderam força e apogeu, o manual didático Processologia na Escola
Primária, de Caio de Figueiredo Silva, aqui analisado, documenta uma forma de apropriação do discurso pedagógico dominante, a modelação desse discurso em prática pedagógica e, principalmente, os complexos processos de articulação realizados entre concepções pedagógicas e método de ensino. Permite também comentar sobre os processos de inovação, permanência e mudança no campo educacional.

\section{O manual Processologia na Escola Primária}

$\mathrm{Na}$ ocasião da publicação do livro Processologia na Escola Primária, seu autor, Caio de Figueiredo Silva, exercia a função de Inspetor Escolar na cidade de São Carlos-SP, tendo uma inserção razoavelmente expressiva no campo dos impressos destinados aos professores no período subseqüente. Publicou vários artigos no periódico Revista do Professor (Silva, 1957a, 1957b; Silva, 1958a, 1958b; Silva, 1959a, 1959b), neles, argumenta em favor da qualificação docente enfatizando a necessidade de conhecimento sobre a psicologia humana e em especial sobre a psicologia da infância, considerada o ponto de origem da evolução das teorias educacionais. Afirma que os princípios norteadores da prática docente são encontrados na psicologia e em sua contribuição para a concepção de infância, que devem constituirse no principal referencial para a proposição de atividades a serem desenvolvidas em sala de aula (Silva, 1957b). Faz também duras críticas aos defensores do tradicionalismo da escola pública, já que acredita que este sistema se transforma numa espécie de "competição-luta que expõe o melhor dotado à adoração, ao endeusamento, da mesma forma que os menos capacitados à execração, à humilhação" (Silva, 1958a, p. 17). Para o autor, cabe à escola suprir as exigências dos alunos com maiores dificuldades, por meio de recursos que tornem a matéria mais interessante $\mathrm{e}$ relevante para sua vida. Alinha-se às novas concepções, especialmente no que se refere à compreensão do papel do aluno, foco principal do trabalho pedagógico que se pretende adequado aos interesses e necessidades específicas da infância. A colaboração de Silva na imprensa periódica, bem como a produção do manual didático, evidenciam coerência com o que entende ser a função do Inspetor Escolar: minimizar a atividade fiscalizadora, transformando- 
se num profissional que apóia o trabalho do mestre; contribuir para a melhoria dos métodos pedagógicos e do próprio educador; realizar a investigação prática dos programas e suas falhas; propor reuniões pedagógicas e a criação de centros de estudo sistemáticos (Silva, 1958b).

O manual didático Processologia na Escola Primária, está presente no corpus documental examinado por Vivian Batista da Silva (2001) composto por livros escritos para a Escola Normal que apresentem "saberes tidos como 'essenciais' a respeito de educação e ensino, visando orientar a prática pedagógica dos professores" (p. 31). O exemplar aqui analisado se peculiariza nesse conjunto pela exposição de noções práticas acerca do fazer docente, descrevendo minuciosamente métodos apropriados para desenvolvê-lo e apoiando-se em idéias que se autodenominam inovadoras. Na designação estabelecida por Choppin (2004) esse tipo de livro escolar exerce as funções referencial (explicita ou interpreta programas de ensino e seleções culturais), instrumental (propõe métodos de ensino, exercícios e atividades) e ideológica (atua como instrumento de construção de identidades e aculturação).

Caio de Figueiredo Silva, assim como a maioria de escritores desse tipo de impresso (Bittencourt, 2004) qualifica-se como autor a partir do exercício da profissão, da experiência no magistério e no cargo de inspeção escolar. O crivo da experiência é explicitado na justificativa para a elaboração do manual, nos exemplos de atividades transcritas e, obviamente no conhecimento do autor sobre elas. Embora integre uma tipologia de impressos pedagógicos escritos por profissionais da educação, esse exemplar difere de outros similares quanto ao leitor visado. A maioria dos manuais didáticos publicados no período em questão foi elaborada para uso em disciplinas específicas do Curso Normal, tais como, Pedagogia Geral, Didática e Prática de Ensino, o que não impede seu uso também por profissionais já formados. Processologia na Escola Primária, no entanto, é escrito especificamente para uso de professores em exercício pois não está vinculado a uma disciplina mas, ao currículo a ser desenvolvido na escola primária, em conformidade com as prescrições oficiais.
O livro abrange o conteúdo a ser desenvolvido, da $1^{\mathrm{a}}$ à $4^{\mathrm{a}}$ série do ensino primário, apresentado numa ordem hierárquica de importância, mesma lógica que o mestre deve usar para o ensino. O texto é organizado em três capítulos: o primeiro é dedicado à Leitura (101 páginas), o segundo ao Cálculo (106 páginas) e o terceiro à Linguagem, Geometria, Caligrafia, Desenho, História Pátria, Geografia, Material Didático, Ginástica e Trabalhos Manuais (127 páginas). A ordenação do conteúdo está também dividida em séries e, algumas vezes, até mesmo distribuída nos meses do ano. O conteúdo é apresentado aliado a forma para ensiná-lo, com roteiros de aulas completos que incluem a preparação, o desenvolvimento na sala de aula e as atividades para serem realizadas pelos alunos. A participação do aluno na aprendizagem é enfatizada com a proposição de diferentes materiais e de exercícios que valorizam a compreensão do conteúdo trabalhado, ressaltando-se a necessidade de estimulá-lo para as atividades propostas.

Enquanto documento de época, o manual permite a compreensão, no plano das prescrições, dos mecanismos implícitos ao processo de produção e circulação das idéias pedagógicas, bem como o poder discursivo que exercem enquanto normalizadores de práticas docentes. No mesmo texto estão presentes o campo, os objetos e os objetivos da intervenção escolar, desdobrados em procedimentos prescritos para alunos e professores, articulados de um modo específico. Não há capítulo dedicado especialmente aos fundamentos ou doutrinas pedagógicas; na introdução de cada um dos conteúdos apresenta-se a justificativa para sua presença no currículo da escola primária e afirma-se a necessidade de fazer uso do interesse lúdico da criança, da "mesa de leitura" na sala de aula, do "cantinho de novidades" e do recurso às dramatizações. É possível observar a tentativa de propor atividades que reforçam e incentivam a autonomia do aluno e a prescrição metódica e minuciosa do trabalho docente, planejado passo a passo e cuja variabilidade já se encontra sugerida. Parece haver consenso quanto aos fundamentos educacionais sendo desnecessário explicitá-los bastando apenas mencioná-los como regras gerais. 
Quanto à importância da leitura, o autor afirma que:

Saber ler, adquirir o hábito de ler ou o desejo de abrir um volume, um jornal, revista, ou qualquer papel em que algo possa haver de interessante ou instrutivo deve ser, portanto, das maiores preocupações da escola elementar, mesmo quando essa escola se desviou do meio-termo sempre mais aconselhável, descambando para um exagerado utilitarismo que só admita se ensine aquilo de que a criança necessite em sua futura vida prática (Silva, 1956, p. 13).

Nessa matéria, recomendando a obra Como se ensina a leitura, da autoria de Wary Pennell e Alice Cusack, está prescrito até mesmo o tempo destinado à motivação dos alunos (cerca de 3 minutos), uma série extensa de perguntas a serem feitas, a prescrição do uso de gravuras, objetos, poemas e excursões. Aponta a necessidade do professor saber avaliar as dificuldades gerais do aluno, sugerindo o modo de fazê-lo. Esse processo pressupõe que seja analisada antecipadamente a extensão do trecho a ler, o interesse provocado pela lição e o adiantamento da classe. Os bons hábitos de leitura devem ser modelados com observação constante sobre a colocação do livro na mesa mantendo determinada distância dos olhos, o modo correto de folhear, o emprego e as finalidades das diversas partes do livro (índice, vocabulário, títulos, capítulos, etc.) e dos recursos auxiliares (vocabulários ortográficos ou dicionários), a correta posição do corpo para leitura e a necessidade de concentração.

Nessas prescrições a perspectiva racionalizadora acerca do fazer docente se manifesta nos mínimos detalhes, orientando e formatando o trabalho com vistas à máxima eficiência das situações propostas, as quais terão êxito mediante a consecução de determinadas condições. Neste sentido, o autor chega listar as condições ideais para as quais o professor deve atentar com vistas à formação do leitor.

$\mathrm{Na}$ etapa da leitura silenciosa (que tem um tempo estipulado de execução de 1 a 4 minutos), o professor deverá andar pela sala verificando a execu- ção das advertências. Ao indicar a necessidade de diálogos sobre o texto lido, o autor sugere uma lista de perguntas a serem feitas pelo professor - tratam-se de 99 perguntas sugeridas para um texto de 16 linhas.

Esse Manual caracteriza-se, entre outros elementos, pela grande quantidade de atividades que sugere ao professor para desenvolver em sala de aula. Ao finalizar o capítulo sobre o ensino da leitura estão listadas pelo menos 40 atividades que abrangem verificação de dificuldades presentes na aprendizagem, fixação do que foi aprendido, implementação da rapidez na leitura, análise de textos, organização (em grupos) do jornal da classe, da mesa de leitura, de festas literárias, entre outras. Dado o grande volume de atividades sugeridas, fica implícita a possibilidade de escolha do professor, mediante suas necessidades e as da classe.

A adesão às idéias escolanovistas pode ser percebida nas atividades propostas: as prescrições apresentadas evidenciam a tentativa de fazer com que a criança domine o processo de leitura compreensiva (ler é penetrar no pensamento oculto representado pelos símbolos gráficos e a formação de bons hábitos de leitura) de modo a driblar a mecanização e a memorização; recomenda a abolição da leitura em coro e de sua repetição. A leitura deve permitir experimentar novas sensações e deve-se respeitar a denominada "lei do interesse" para a formação do hábito, o que ocorrerá na medida em que forem escolhidos temas relacionados ao universo infantil, desencadeando a motivação no decorrer das lições, as quais devem ser mediadas por uma seqüência de questões que prevêem a participação ativa da turma. Esperase assim, desenvolver a formação do hábito de leitura e do hábito de julgar, por ângulos variados, o material que é lido, bem como a capacidade de leitura oral e silenciosa e de escolher o que se deseja ler.

Atendendo às peculiaridades de aprendizagem do aluno, o autor credita à etapa inicial das aulas uma grande importância dado que seu objetivo é despertar-lhe o interesse. Assim, a preparação para a leitura deve funcionar como um "trailer" cinematográfico, apresentando algumas cenas que permitam formar uma idéia sobre o todo, aprendido por meio de leitura silenciosa e depois, de resposta às questões 
formuladas pelo professor. A última etapa do processo de leitura abrange leitura oral, o aproveitamento em aula de outra matéria, dramatização, ilustração e elaboração de trabalho escrito sobre a lição. Nelas, é possível verificar também a tentativa de incentivar o exercício da autonomia do aluno, criando jornais de classes, organizando festas literárias e realização de trabalhos em grupo. Essas atividades são justificadas sempre como adequadas para despertar e manter o interesse, bem como para a avaliação da aplicabilidade do que foi aprendido com a escolha de temas presentes no cotidiano escolar.

O ensino do cálculo está associado a um forte apelo aos recursos ilustrativos devido à crença de que possibilitariam compreensão do assunto proposto. Essa característica, também pode ser observada numa série organizada por Caio de Figueiredo Silva, intitulada Nossa Vendinha ${ }^{2}$, editada no ano de 1950. Nesse conteúdo, a vinculação do conhecimento com a vida explicita-se muito claramente, embora ele seja justificado também pelo desenvolvimento da capacidade de raciocinar, incrementar a memória e a exatidão. $\mathrm{O}$ início da aprendizagem se dará com objetos e, posteriormente, serão utilizadas a escrita e a oralidade. A tentativa de evitar a mecanização e a memorização se dá com a realização de inúmeros cálculos (das operações elementares) para resolução oral. Após a aprendizagem das operações, podem ser resolvidos os problemas cujo enunciado exige compreensão adequada e para tanto, o professor pode valer-se de ilustrações de modo que o aluno, fazendo a operação inversa, formule o problema a ser resolvido. No ensino da tabuada não há indícios de inovação: ela preci-

\footnotetext{
${ }^{2}$ A série, apresentada como uma espécie de caderno para o aluno, contém exercícios organizados a partir de uma ilustração no início da página, da qual são extraídas situações matemáticas. Os cadernos são divididos por série, sendo um por semestre, com exceção do $1^{\circ}$ ano, organizado num único caderno. A capa da série contém uma ilustração que mostra crianças em situações de uso cotidiano da matemática num estabelecimento comercial (vendinha), com moedas nas mãos que, possivelmente, seriam entregues ao senhor que pesa algo que será adquirido pelo casal de crianças. Também constam na capa a data de publicação (18/05/1950) e número da patente da série (8291), publicada pela Editora do Brasil, além de espaço para anotar as seguintes informações: estabelecimento, aluno, professor, classe.
}

sa ser memorizada dada sua imprescindibilidade para o ensino desse conteúdo. No entanto, essa característica pode ser minimizada com a prática sistemática das tabuadas por meio de jogos e competições, evitando-se o denominado "complexo de inferioridade matemática” (Silva, 1956, p. 205) que consiste na incapacitação e inibição frente a um problema que exige o conhecimento prévio da tabuada ainda não automatizado. Condena a mecanização do ensino de cálculo e enfatiza o processo que privilegia o desenvolvimento do pensamento lógico-matemático, expondo algumas diretrizes que visam evitar que o raciocínio seja substituído pelo hábito de resolver situações matemáticas baseadas em questões de padrão estático ou perguntas que induzam a resposta, sem a preocupação com a compreensão da situação proposta. Afirma ainda que a aritmética realmente empregada na vida é bem mais simples que aquela ensinada na escola, sugerindo a supressão de uma boa parcela do que consta nos Programas Oficiais.

A expressão, intimamente ligada à linguagem, depende do meio em que vive a criança e por isso, a redação e a ortografia são recursos indispensáveis na formação escolar. O ensino da linguagem nas primeiras séries tem como objetivo o domínio da expressão, a clareza e a simplicidade e por isso deve iniciar-se oralmente com diálogos sobre o cotidiano, valendo-se de jogos e brincadeiras que garantam a motivação. A aprendizagem da linguagem escrita começa com a cópia de palavras, a partir das quais são destacadas as sílabas, combinações, inserções em frases, etc. Nessa etapa é indicada a confecção do "Dicionário do aluno" (caderno no qual lança as palavras novas). As cópias são recurso necessário, mas devem ser alternadas com formação de sentenças, organização de seqüências, composição e reprodução de historietas, redação de bilhetes e pequenas cartas e ditados. Nas séries mais avançadas o professor pode propor que os próprios alunos elejam a melhor narração entre aquelas realizadas pela classe. As atividades de linguagem devem ser iniciadas sempre pela oralidade, numa conversa sobre determinada gravura, sintetizada depois em um sumário na lousa que possibilita a organização das idéias. Ao final desse processo, chega-se à expressão escrita no caderno, sobre a qual o aluno deve exercer 
autocrítica, relendo cuidadosamente o que escreveu e corrigindo os erros encontrados (exercício feito com bastante freqüência).

Nesta perspectiva, o aluno deve tornar-se responsável pela melhoria de seu aprendizado, desenvolvendo autocrítica em relação a sua produção. Esse processo se dá principalmente por meio do hábito de reler suas atividades com o intuito de diminuir a incidência de erros, exercendo assim papel ativo no processo de correção. Dado que todas as atividades devem ser planejadas levando em conta as especificidades infantis, o autor sugere motivá-las com o uso de jogos e situações que garantam prazer em sua realização. No que se refere às correções, indica-se uma série de possibilidades didáticas visando evitar que as incidências de erros possam se transformar em algo frustrante e desmotivador. Orienta ainda para que se dê aos erros uma conotação natural e que a correção não abale psicologicamente a criança.

No que se refere ao ensino da Geometria, o autor critica a extensão do conteúdo proposto no Programa Oficial e propõe que o professor se atenha às noções práticas e utilitárias, apresentadas de forma interessante à criança, privilegiando as noções de superfície e volume, os sólidos, as figuras geométricas e sua aplicação nos desenhos decorativos. Iniciando com argila, massa plástica, cartolina e papel serão modeladas as formas geométricas e depois objetos que tenham tais formas e que possam resultar em usos lúdicos e recreativos.

No ensino da Caligrafia, guiado pelo livro de Orminda Marques $A$ escrita na escola primária, referendado por Lourenço Filho, recomenda que o treinamento do processo muscular se dê com movimentos sem aplicação em palavras e à lápis e nos anos finais executam-se os mesmos movimentos com maior exigência de rapidez e forma e escritos à tinta. Para afastar o tédio e a repetição mecanizada podem ser utilizados desenhos e cantos. Ao aprendizado da caligrafia, grosso modo entendido como um processo meramente mecânico, o autor atribui uma importante função relacionada à formação de hábitos indispensáveis para todas as atividades que compõem o currículo escolar. O ensino do desenho também é valorizado pelo prazer que proporciona à criança e pelas possibilidades de uso para expressão das idéias e ilustração de situações que permeiam todos os conteúdos.

O ensino da História Pátria, além de estimular a admiração pelos nossos feitos e o orgulho pelos nossos ancestrais, não deve se ater à memorização de datas e nomes. Criticando o uso de cadernos impressos, o autor propõe que o aluno organize seu próprio texto a partir de um sumário proposto pelo professor no quadro-negro no decorrer da exposição, ponto de partida para a explanação sobre o tema. Em casa, esse sumário será transformado pelo aluno num texto a ser apresentado à classe na aula subseqüente, possibilitando a correção da produção.

No que se refere ao ensino da Geografia, recomenda evitar a lista de pontos a serem memorizados e o retorno a sua função de conhecer os hábitos e costumes dos diferentes povos, favorecendo a real aproximação entre os homens. Para esse objetivo contribuirão diversos materiais como filmes, mapas, excursões, atlas, globo, revistas ilustradas, tabuleiro de areia para o estudo do relevo, caderno de recortes, entre outros. $\mathrm{O}$ autor considera esse conteúdo o mais adequado ao uso dos testes para a verificação da aprendizagem, pois permite recorrer às analogias, à complementação de frases e às múltiplas escolhas.

Compondo o currículo escolar há ainda a Ginástica que, além de exercícios físicos, agrega brincadeiras, preceitos de higiene e avaliação física do aluno. O ensino de Trabalhos Manuais propicia o uso da imaginação fértil das crianças e maiores recursos de expressão, uma vez que não pode haver escola ativa sem atividade manual.

Assim, é possível perceber nas atividades prescritas para o aluno a incorporação do ideário escolanovista por meio da prescrição de atividades que valorizam a autonomia do aluno, sua participação ativa no processo de conhecimento, o recurso aos aspectos lúdicos e construtivos. Alguns conteúdos são mais permeáveis a esses objetivos, tais como, língua portuguesa e história pátria para as quais são sugeridas atividades de pesquisa, criação de textos com discussões coletivas; em outros, a transição para a nova concepção de aprendizagem restringe-se a atividades ligadas ao cotidiano do aluno, como cálculo e geometria que incorporam problemas com transações financeiras e medidas de áreas familiares às crianças. 
O mesmo não se pode dizer quanto às orientações para o professor presentes no manual: elas não evidenciam incentivo à autonomia na prática docente nem demonstram confiança na capacidade do professor para elaborar atividades. O ensino do cálculo, por exemplo, é apresentado de modo bastante detalhado descrevendo sua marcha, o que deve ser posto no quadro-negro, o que deve ser apenas explicado e o que deve constar no caderno do aluno. Estão descritas a divisão do conteúdo na seqüência anual das aulas e quais itens do programa devem ser precedidos de revisões. Os roteiros de aula contêm sugestão de material de apoio, exemplos para serem utilizados durante a explanação, a quantidade de exercícios diários, a variação de atividades para sedimentar o conhecimento (no ensino do cálculo 35 páginas são dedicadas à sugestão de exercícios para aprimoramento das quatro operações). Ancorado na observação dos erros mais freqüentes na processologia do Cálculo, o autor adianta-se a eles descrevendo sua ocorrência e possibilidades de superá-los.

A exposição do conteúdo a ser ensinado e do método para fazê-lo não impede a afirmação que o resultado positivo ou negativo depende da habilidade do professor na sua execução. Ao apresentar algo que considera inovador, descreve também o que não seria recomendável, embora seja prática encontrada nas escolas, fornecendo material para o professor avaliar seu desempenho ou, melhor ainda, chegar ao “eu fazia assim e agora faço assim”. No entanto, responsabiliza os dirigentes do ensino pelo fato de os professores ainda não terem incorporado práticas condizentes com os novos fundamentos pedagógicos.

São indicados todos os procedimentos para a correção dos erros, embora ela "deva ser comedida, a fim de que não se exija da criança inexperiente aquilo que ainda não seja capaz" (Silva, 1956, p. 266). No caderno do aluno deverão ser assinalados erros que representem perigo de transformarem-se em hábitos (troca de letras, por exemplo). Para evitá-los, o professor deverá apagar o erro e escrever corretamente repetindo a palavra na margem do caderno; erros provocados por falta de atenção deverão ser apenas apontados e corrigidos pelo próprio aluno; erros mais graves e de difícil percepção pela criança, deverão ser corrigidos com caneta vermelha e copiados várias vezes pelos alunos.

Prescreve que em todas as aulas, antes de iniciar os exercícios de linguagem, deve-se fazer com que a classe permaneça de dois a três minutos num trabalho mental, ficando de mãos abertas ao lado do rosto, evitando distrações da vista, deixando, portanto, o lápis ou caneta sobre a carteira. E que após o término do trabalho, o professor deveria ainda destinar de dois a três minutos para o exercício de autocorreção, pedindo que cada aluno encontre pelo menos um erro em seu exercício. Salienta que a avaliação de tais preceitos só pode ser feita após sua aplicação por um longo período de tempo, evitando-se assim a prática de abandonar inovações "por não apresentarem bons resultados de imediato" (Silva, 1956, p. 282).

Para o ensino da geometria, ilustra detalhadamente todas as atividades, orientando o professor na construção de sólidos que serão transformados em objetos, com o auxílio de pintura e colagens.

Os exercícios prescritos para o início do ensino da caligrafia devem ter sempre a escrita do professor como modelo e a ele cabe observar a correta posição do caderno, do ante-braço e das mãos. Valendo-se do canto e dos compassos musicais para a aquisição do ritmo e harmonia, a marcha dos exercícios inicia-se no ar, passando para a lousa e, posteriormente para o caderno.

Silva (1956) afirma que muitos professores, por não terem facilidade para desenhar (habilidade que não é desenvolvida nos cursos de formação) não sabem dar a esta disciplina o valor que merece, isto é, considerá-la um tipo de atividade mental que permite dar forma às experiências visuais.

Quanto ao ensino de ginástica, afirma que os professores poderão ser preparados em clubes de Educação Física ou por especialistas da área mas, ao lado das prescrições higiênicas (local, uniforme, temperatura), o autor descreve 50 tipos de jogos e inúmeros movimentos a serem trabalhados nas aulas.

\section{A difícil articulação entre inovação e tradição}

No que se refere à prática prescrita, o texto do manual busca inserir-se no campo dos saberes peda- 
gógicos por meio da elaboração de discurso que se justifica como veículo de uma nova proposta para o ensino das diversas disciplinas que compõem o currículo. Como recurso de legitimidade, o autor vinculase ao discurso do novo, em oposição à prática vigente. Enquanto literatura pedagógica justifica diferenciar-se da "feição teórica" da grande maioria de obras direcionadas ao exercício docente, afirmando que o diferencial de seu texto é o "cunho utilitário, que deveria caracterizar toda obra destinada ao professor de primeiras letras" (Silva, 1956, p. 9).

Assim, esse impresso materializa uma forma de apropriação da teoria pedagógica que se evidencia na articulação com a prática docente prescrita. As diretrizes gerais são incorporadas ao discurso justificador das atividades propostas e dos conteúdos selecionados mas já com a feição de slogans. É possível também perceber o esforço para incorporar as mesmas diretrizes às atividades a serem realizadas pelos alunos criando situações para valorizar a autonomia na aquisição do conhecimento e o vínculo com as necessidades presentes na vida cotidiana.

As proposições põem em evidência o aluno, tornando-o centro do processo e ganham força de legitimidade por incorporarem ao discurso sínteses simplificadas de teoria pedagógica complexa. Desse modo, ainda que a teoria da Escola Nova não seja fielmente traduzida, o impresso passa a se apresentar como veículo da renovação, na medida em que organiza um conjunto de idéias que visam disseminar um capital de crenças que incorporadas constituirão o que Bourdieu (1992) nomeia "habitus de classe".

Pode-se dizer ainda que a publicação do manual corresponde a uma tentativa de responder às necessidades expressas nos programas oficiais, pois prescreve métodos que visam tornar ensináveis os conteúdos previstos.

Souza (2006) descreve as dificuldades enfrentadas pelos educadores no estado de São Paulo para conciliar os preceitos escolanovistas, em termos de prescrições curriculares, com o controle da atividade pedagógica. Num processo que vai de 1930 a 1950 , as posições oficiais alternam-se entre programas analíticos e sintéticos, isto é, os primeiros com descrições minuciosas do que deveria ser ensinado e os segundos contendo orientações gerais. $\mathrm{Na}$ reformulação dos programas ocorrida em 1949-1950 “prevaleceu a orientação analítica, revelando a preferência da equipe responsável pela prescrição detalhada dos procedimentos de ensino" (Souza, 2006, p. 151). Nesta perspectiva, pode-se entender o esforço de Caio de Figueiredo Silva na descrição pormenorizada do processo de ensino a ser observado em todos os conteúdos, coerentes com as orientações oficiais paulistas, embora faça críticas ao seu caráter enciclopédico. Não pode ser minimizada também a posição do autor na hierarquia escolar: as sugestões apresentadas adquirem o peso de orientações legais.

O predomínio do discurso normativo dos programas oficiais justifica a produção de uma literatura que ordene de modo seriado os conteúdos escolares, além de dar a eles uma conotação prática. O texto do manual didático Processologia na escola primária, desde o título se enquadra nesta perspectiva e a adoção da obra nos cursos de formação profissional atesta a receptividade deste estilo de publicação que oferece respaldo prático para o professor baseado em práticas bem sucedidas.

O texto ilustra também a complexa articulação sempre presente quando se trata de harmonizar concepções teóricas e procedimentos didáticos, onde intervêm inúmeros fatores presentes no campo pedagógico. As atividades propostas para os alunos incentivam a autonomia na aprendizagem, a auto-avaliação e a significação do conhecimento. O mesmo não se pode dizer sobre a concepção do trabalho docente subjacente às prescrições do manual. Mais do que modelos de aula e de atividades, o texto apresenta um programa escolar pronto para ser executado. Prescreve-se o conteúdo a ser ensinado, a forma de fazê-lo, as variações de exercícios, antecipam-se as dificuldades e propõem-se soluções para elas. Não há espaço nem incentivo para a autonomia do professor ou para a auto-avaliação.

Focalizando o olhar no processo de transposição didática, relacionando os princípios sobre o conhecimento em geral e as prescrições metodológicas para o ensino, pode-se perceber o papel desempenhado pelos manuais na formação de tipos específicos de raciocínio de professores e alunos. Os mode- 
los de aulas e de atividades dirigem-se aos professores, exemplificando o raciocínio adequado para a atividade docente.

A análise do corpo dos manuais, de sua parte mais substancial, permite, além de verificar, visualizar a seleção cultural ali levada a efeito. Trata-se de um recorte da cultura estabelecido a partir da legislação em vigor, por meio da qual constitui-se uma reinterpretação configurada num currículo, por sua vez, desdobrado em programas de ensino de cada um dos conteúdos. Dito de outro modo, a prescrição metodológica nos manuais é exercitada sobre um conteúdo a ser ensinado, dividido em disciplinas escolares que, juntas, compõem o currículo escolar. Essa configuração da cultura permite analisar o processo de introdução, transformação e permanência dos conteúdos e disciplinas, bem como sua valorização em determinado contexto histórico. Estamos assim diante de um conteúdo que, valendo-se de inúmeras formas e dispositivos de inculcação e repetição, garante sua continuidade legitimando a criação de comunidades, de sistemas de valores, de padrões de comportamento e de mecanismos de diferenciação social através da constituição do hábito culto, que diferencia os participantes do sistema educacional (Bourdieu, 1992). A exposição do conteúdo e da metodologia apresentada nos manuais possibilita avaliar de quantos mecanismos se vale a instituição escolar para proceder a inculcação de valores e padrões de comportamento, num processo bem mais complexo do que quando avaliado apenas na perspectiva da ideologia de uma classe social.

É preciso considerar, no entanto, que a produção desse tipo de impresso atende a uma demanda do próprio sistema educacional. A análise de periódicos educacionais realizada por Cunha (1992) evidencia as diferentes fases e ênfases na difusão do ideário escolanovista no Brasil e constata que:

Apesar de todo o esforço desenvolvido desde as primeiras décadas do século, em fins dos anos cinqüenta se percebe que o ensino tradicional ainda persiste, com o mesmo elitismo que o caracterizava desde o princípio. Os professores, embora recebam uma formação que os coloca em contato com os postulados escolanovistas, não possuem capacitação prática para exercitar esses conhecimentos; além disso, não encontram, na escola pública, uma estrutura que permita a efetivação dos ideais renovadores (Cunha, 1992, p. 220)

Pode-se arriscar uma interpretação com a hipótese que, valendo-se de sua posição de inspetor escolar, Caio de Figueiredo Silva faz uso do impresso para impor a inovação nos métodos de ensino. A forma do manual, no entanto, denuncia o peso que a tradição pedagógica de prescrição rígida e detalhada tem na concepção de formação de professores.

Esses exemplos extraídos do manual em análise permitem afirmar que a influência da pedagogia renovada se dá principalmente no plano discursivo, com a incorporação de idéias simplificadas de suas proposições. No que se refere às práticas, há a incorporação de algumas inovações em termos de atividades, mas mantém-se a estrutura formal das aulas divididas em lições, nitidamente estruturadas de modo a compor o programa de ensino determinado oficialmente.

Se os programas escolares são sempre lembrados como impedimento para a inovação pedagógica, conforme também apontado por Souza (2006), deve-se considerar também que, ao explicitarem a pretensão de operar uma mudança de mentalidade no professorado brasileiro, os divulgadores da Escola Nova no Brasil explicitaram um projeto de longa duração, característica dos processos da esfera cultural. E embora tenham colocado em segundo plano a conformação das práticas são elas as responsáveis por dar significação aos elementos conceituais. Ao ensaiar e crivar as inovações pela experiência, está em construção um processo seletivo da teoria que conforma as apropriações e os manuais didáticos, atingindo um grande público durante um longo período de tempo cujas sucessivas edições têm papel determinante nesse projeto cultural.

\section{Referências}

Bastos, M. H. C. (2005). A Revista do Ensino do Rio Grande do Sul (1939-1942): O novo e o nacional em revista. Pelotas, RS: Seiva. 
Biccas, M. de S. (2001). O impresso como estratégia de formação de professores(as) e de conformação do campo pedagógico em Minas Gerais: O caso da Revista de Ensino: 1925-1940. Tese de doutorado não-publicada, Faculdade de Educação, Universidade de São Paulo, São Paulo.

Biccas, M. de S. (2005). "Nossos Concursos" e "A Voz da Prática": A Revista do Ensino como estratégia de formação de professores em Minas Gerais (1925-1930). Cadernos de História da Educação, 4, 155-166.

Bittencourt, C. M. F. (2004). Autores e editores de compêndios e livros de leitura. Educação e Pesquisa, 30, 475-491.

Bourdieu, P. (1992). Campo de poder, campo intelectual e habitus de classe. In S. Miceli (Org.), A economia das trocas simbólicas (S. Miceli, S. de A. Prado, S. Miceli \& W. C. Vieira, Trad.). São Paulo: Perspectiva.

Campos, D. G. dos S. (2005). A complexa articulação entre concepções pedagógicas e método de ensino: Manual didático e imprensa periódica: As estratégias de inovação sobre como ensinar (1940-1960). Dissertação de mestrado não-publicada, Faculdade de Ciências e Letras de Araraquara, Universidade Estadual Paulista, Araraquara.

Carvalho, M. M. C. de (2001). A caixa de utensílios e a biblioteca: Pedagogia e práticas de leitura. In D. G. Vidal \& M. L. S. Hilsdorf (Orgs.), Brasil 500 anos: Tópicas em história da educação (pp. 137-167). São Paulo: Edusp.

Carvalho, M. M. C. de (2002). Pedagogia da Escola Nova, produção da natureza infantil e controle doutrinário da escola. In M. C. Freitas \& M. Kuhlmann Jr. (Orgs.), Os intelectuais na história da infância (pp. 373-408). São Paulo: Cortez.

Carvalho, M. M. C. de, \& Toledo, M. R. de A. (2004). A coleção como estratégia editorial de difusão de modelos pedagógicos: $\mathrm{O}$ caso da Biblioteca de Educação, organizada por Lourenço Filho. In Seminário Brasileiro sobre livro e história editorial, 1. Rio de Janeiro: Casa de Rui Barbosa.
Carvalho, M. M. C. de, \& Toledo, M. R. de A. (2006). A Biblioteca de Educação de Lourenço Filho: Uma coleção a serviço de um projeto de inovação pedagógica. Quaestio (UNISO), 8, 47-63.

Carvalho, M. M. C. de, \& Toledo, M. R. de A. (2007). Os sentidos e a forma: Análise material das coleções de Lourenço Filho e Fernando de Azevedo. In M. A. T. Oliveira (Org.), Cinco estudos em história e historiografia da educação (pp. 89-110). Belo Horizonte: Autêntica.

Catani, D. B., \& Bastos, M. H. C. (Orgs.). (2002). Educação em Revista: A imprensa periódica e a história da educação. São Paulo: Escrituras.

Catani, D. B. (2003). Educadores à meia-luz: Um estudo sobre a Revista de Ensino da Associação Beneficente do Professorado Público de São Paulo (1902-1918). Bragança Paulista, SP: EDUSF.

Choppin, A. (2004). História dos livros e das edições didáticas: Sobre o estado da arte. Educação $e$ Pesquisa, 30(3), 549-566.

Cunha, M. V. da (1992). Individuo e sociedade no ideário escolanovista (Brasil: 1930-1960). Tese de doutorado não-publicada, Faculdade de Educação, São Paulo.

Lopes, S. de C. (2006). Oficina de mestres: História, memória e silêncio sobre a Escola de professores do Instituto de Educação do Rio de Janeiro (1932-1939). Rio de Janeiro: DP\&A.

Lourenço Filho, M. B. (1978). Introdução ao estudo da Escola nova: Bases, sistemas e diretrizes da pedagogia contemporânea (12a ed.). São Paulo: Melhoramentos.

Monarcha, C. (1997). Lourenço Filho e a Bibliotheca de Educação. In C. Monarcha (Org.), Lourenço Filho: Outros aspectos, mesma obra (pp. 2757). Campinas, SP: Mercado de Letras.

Pimenta, M.A. (1952). A situação atual no ensino na escola primária. Revista de Educação, 38(62), 83-89. 
Pinto, K. P. (2006). Por uma nova cultura pedagógica: Prática de ensino como eixo da formação de professores primários do Instituto de Educação do Rio de janeiro (1932-1937). Tese de doutorado não-publicada, Pontifícia Universidade Católica, São Paulo.

Silva, C. de F. (1956). Processologia na escola primária (Coleção Didática do Brasil, Vol. 2). São Paulo: Ed. do Brasil.

Silva, C. de F. (1957a). Educação século XX. Revista do Professor, 15(33), 5-6.

Silva, C. de F. (1957b). O mestre de meus filhos. Revista do Professor, 15(35), 5-6.

Silva, C. de F. (1958a). Evolução. Revista do Professor, 16(42), 5-6.

Silva, C. de F. (1958b). Problema em tela. Revista do Professor, 16(38), 17-18.

Silva, C. de F. (1959a). Considerações sobre o ensino da linguagem. Revista do Professor, 17(47), 25-27.

Silva, C. de F. (1959b). Modificação que se impõe. Revista do Professor, 17(45), 25-26.

Silva, V. B. da (2001). História de leituras para professores: Um estudo da produção e circulação de saberes especializados nos “manuais pedagógicos” brasileiros (19301971). Dissertação de mestrado não-publicada, Faculdade de Educação, Universidade de São Paulo, São Paulo.

Souza, R. F. de (2006). Alicerces da pátria: Escola primária e cultura escolar no estado de São Paulo (1890-1976). Tese de livre docência nãopublicada, Faculdade de Ciências e Letras, Universidade Estadual Paulista, Araraquara.

Toledo, M. R. de A. (2001). Coleção Atualidades pedagógicas: Do projeto político ao projeto editorial (1931-1981). Tese de doutorado não-publicada, Pontifícia Universidade Católica, São Paulo.

Vidal, D. G. (2001). O exercício disciplinado do olhar: Livros, leituras e práticas de formação docente no Instituto de Educação do Distrito Federal (1932-1937). Bragança Paulista, SP: EDUSF.
Viñao F. A. (2006). Sistemas educativos, culturas escolares y reformas (2a ed.). Madrid: Ediciones Morata.

Artigo recebido em 09/08/2007.

Aceito para publicação em 18/12/2007.

Apoio Financeiro: $\mathrm{CNPq}$

Endereço para correspondência:

Vera Teresa Valdemarin. Av Espanha, 60 apto 31. CEP: 148010-130, Araraquara-SP, Brasil. E-mail: vera@fclar.unesp.br

Vera Teresa Valdemarin é Professora Adjunta do Departamento de Ciências da Educação, docente do Programa de Pós-graduação em Educação Escolar da Faculdade de Ciências e Letras de Araraquara/Universidade Estadual Paulista Júlio de Mesquita Filho.

Daniela Gonçalves do Santos Campos é Mestre em Educação Escolar pelo Programa de Pósgraduação em Educação Escolar da Faculdade de Ciências e Letras de Araraquara/Universidade Estadual Paulista Júlio de Mesquita Filho, professora da Faculdade de Itápolis (FACITA). 